spiritual from the material, creating a dualism, because it ignores nursing tradition? The origins and development of nursing and the ethic of whole person care, both historically and culturally, derive from a view of the person as irreducibly and inseparably a material and spiritual creation. Although growing ever weaker, this ethic is still implicit in nursing. As the interviewed nurses assume, and as the authors are eventually forced to recognise, spiritual care is not a selfconscious addition to nursing care but the very way of love.

Despite the price this book will undoubtedly become a nursing textbook on spirituality but I hope that it will also form part of a wider academic debate in nursing. For those outside nursing this book is a window into modern nursing theory.

ANN BRADSHAW National Institute for Nursing, Oxford

\section{At women's expense: state power and the politics of fetal rights}

\author{
Cynthia R Daniels, Cambridge, \\ Massachusetts, Harvard University \\ Press, 1993, 183 pages, $£ 15.92$ hc
}

The language of maternal-fetal conflict, this book's concern, is now part of English law. In the recent $S$ case a Caesarean section was ordered on a pregnant woman against her will, despite her previous successful vaginal delivery when doctors had also predicted that only a section could save the baby. Now there is great uncertainty about the longstanding common-law tradition that the fetus has no legal personhood.

The $S$ judgment - which has been denounced by the Royal College of Obstetricians and Gynaecologists cited the 1987 US case of Angela Carder, a young woman with cancer who became pregnant while in remission. She agreed that a Caesarean section could be performed if necessary after the twenty-eighth week of pregnancy, the point at which her attending physicians thought the fetus stood an acceptable chance of survival. In the twenty-fifth week of her pregnancy she took a radical turn for the worse. The trial judge ruled that she had no interests because she was dying, and that the survival of the fetus was the priority despite its poor prognosis.
The baby died within two hours of the operation; Angela Carder died two days later, having regained consciousness long enough to learn that her child was dead.

After Carder's death the trial court decision was reversed, and women's right to bodily integrity re-stated firmly by the US Court of Appeals. Yet as Daniels ably and convincingly argues, there are many countervailing straws in the wind. Carder had not viewed herself as in conflict with her baby; she gave permission for the Caesarean at the age of likely fetal viability, knowing the risk to herself. The conflict was in the eye of the beholder, the trial judge; but the assumption of conflict between mother and fetus has now become general, Daniels argues. Although no one, not even a parent, can be forced to donate an organ to a relative, pregnant women can be and have been forced to have blood transfusions against their will, made to deliver in leg and arm restraints, and physically detained in hospital, particularly if they were suspected of drug use.

How can such mediaeval barbarities occur in what some call the 'post-feminist' age? The new politics of fetal rights is in part a backlash reaction to the comparative success of feminism. The very 'permission' given to women by abortion statutes (in this country) and case law (in the US) has now been turned against them. Once a woman decides to continue with her pregnancy, fetal rights activists argue, she loses the right to bodily integrity. If fetal monitoring, Caesarean section, or restriction of her drug and alcohol intake will benefit the baby, in this consequentalist argument, the state should intervene to protect 'the tiniest citizen'.

Daniels reports from three main battle zones in which the rhetoric of maternal-fetal conflict has affected policy in the United States: medical interventions in pregnancy; 'health and safety' policies which bar all women of childbearing age from certain forms of work unless they can prove they have been sterilised; and prosecutions of pregnant female addicts for 'supplying drugs' through the placenta. Although Daniels concerns herself solely with US case law, in the first two areas the opposing forces have also made inroads into British terrain: through the $S$ case and a 1981 decision in which ICI was allowed to bar women from working with a chemical linked to cancer, rather than try to make the chemical less dangerous.
It is developments in medical technology, as much as the backlash against feminism, which Daniels identifies as the origin of the new fetal rights policies. In the most interesting and original chapter of the book, chapter one, she points out that ultrasound scanning and micro-surgery on the fetus make the mother 'transparent', and thus invisible. Advances in the age of fetal viability and popular misunderstanding of in vitro techniques also contribute to the rhetoric of the independence of the fetus, ie, its ability to survive outside the mother's body. "The women became the "maternal environment", the "operating womb", and even the fetus's "intensive care unit".'

This incisive and insightful book uses the three core areas as a springboard to a broader discussion of the right to self-sovereignty and the inadequacy of its formulation. Although Daniels's discussion is primarily in terms of political theory, there are obvious repercussions for the principle of autonomy in medical ethics. 'Such concepts seem both essential to women's empowerment and yet incapable of capturing the potential, developmental and relational nature of pregnancy or the deeply social nature of reproduction. The politics of fetal rights thus suggests the need to rethink the concept of self-sovereignty from the point of view of the female body.'

DONNA DICKENSON

School of Health and Social Welfare, The Open University

\section{Ethical responsibilities in European drug research}

Edited by Peter N Bennett, Bath, Bath University Press, 1990, 84 pages, $£ 15.00 \mathrm{hc}$

This book contains a series of very short, readable essays on different perspectives on ethical and legal issues in drug research in the EEC. The essays are updated versions of papers given at a symposium held at the Maison de l'Europe of the European Parliament, Strasbourg on 14-15 September, 1989. The symposium was held in the light of recent legislative trends in several European countries which sought to protect the rights of 
individual human subjects of research, and to provide a framework within which medical research could flourish.

The essays begin with a thoughtprovoking philosophical discussion by $\mathrm{Dr} \mathrm{K}$ Boyd. His examination of $\mathrm{Dr}$ K W M Fulford's 'four principles' for research -- knowledge, necessity, benefit and consent - is particularly useful, as these principles can provide a theoretical framework for those whose duty it is to review research protocols. This essay is followed by an informative discussion of the role of the World Health Organisation by Dr M N G Dukes, which has been in a fairly strong and effective position in 'persuading, nudging, catalysing the development of consensus and generally guiding the world into a proper pattern of behaviour on health issues'.

Dr P Bennett then provides an excellent summary of the key concerns of the clinical investigator, which could also serve as a checklist for research ethics committees. Dr N $P$ Maurice, writing from the perspective of the pharmaceutical industry, describes the complexity of European drug trials because of different attitudes to the way human research should be carried out. He discusses the development of 'good clinical practice' and the rise in the 1960s of the disciplines of clinical pharmacology and pharmaceutical medicine.

Dr S L Nightingale of the United States Food and Drug Administration explains in his essay the details of the regulatory system governing clinical research on humans in the United States. This regulatory system is highly developed, with a comprehensive review structure (which includes monitoring standards of review) by institutional review boards (IRBs). $\mathrm{J}$ Dangoumau then discusses the responsibilities of research ethics committees in France, where recent legislation has established local Consultative Committees for the Protection of Individuals.

Mr B Wijnberg offers a comparative overview of legislation in different EEC countries regarding medical research on humans, and of aspects of international and EEC law which impinge on these experiments. He concludes that there is room for improvement.

Dr F Garcia-Alonso and Dr M A Serrano-Castro describe clinical research and its regulation in Spain. This is followed by a discussion of the role of the European Ethical Review Committee by its chairman, Dr W M Rosinga. Finally, Dr Fernand Sauer gives an overview of the ethical aspects of EEC pharmaceutical legislation.

In his concluding remarks the editor notes that there is diversity between countries of the EEC, because of cultural and legal differences. He also points out that there are important points of unity; for example, the almost universal recognition of the Declaration of Helsinki of the World Medical Association. The editor leaves us with a direction: 'to stimulate the establishment of ethical review committees throughout the EEC' and to provide a uniform standard of review across the community.

The symposium must have provided a very useful and informative exchange of views and perspectives, reflected to a certain extent in the essays. Arguably the essays do not examine each topic in enough depth; nonetheless, they certainly lay foundations for further discussion and collaboration between countries of the EEC.

CLAIRE GILBERT FOSTER Centre of Medical Law and Ethics, King's College, London

\section{Animal rights and human morality}

\section{Bernard E Rollin, Buffalo NY,} Prometheus Books, 1992, 248 pages, $£ 12.95 \mathrm{sc}$, revised edition

Bernard Rollin is the stockman's rather than the philosopher's philosopher, having learned his trade in head-on intellectual combat with ranchers, veterinarians and researchers. His preferred method of argument, he writes, is less like sumo than judo: 'I simply side-step and give you a slight encouraging push in the direction of your punch ... and thereby show you that the ideal I am pressing upon you is in fact a consequence of beliefs you yourself entertain' (page 25). Animal Rights and Human Morality abounds in such home-spun wisdom, deceptively simple, since what Rollin wears so lightly is good learning, soundly-based and painstakingly acquired. One does not become a professor of philosophy, physiology and biophysics, simply by rocking-chair moralising.

More than a decade after its first edition, this remains one of the best introductions to its subject, livel lucid and engaging. Its first chapter Moral theory and animals (which makes up about a third of the bools outlines relevant deontological and consequentialist features of tho debate, arguing convincingly that animals have interests and their owf telos, which ought to be respected. 'moral gestalt shift' in perspective however, is needed for most people to realise this, and Rollin is realist about the difficulties involved in bringing this about. A second (much shorter) chapter on Animal rights ant legal rights explores ways of shifting the legal focus from animals property to the rights and welfare $\overline{\text { AP }}$ the animals themselves. Realisn again informs Rollin's third chaptẹp on The use and abuse of animals if research, which proposes a utilitariat cost-benefit principle to determino whether the research should be done at all, and then against that back $_{\overline{\mathrm{T}}}$ ground, a rights principle to maxi mise the potential of the animats involved for living according to the nature.

What Rollin writes about the la $\overrightarrow{0}$ and research largely reflects pra@ic in the USA; and it is tempting to suggest that much of what he recorio mends has already been impleme under recent British legislation. $\mathrm{O} \overline{\overline{\mathbf{Q}}}$ the other hand, many of his com ments on education and attitudes ar pertinent on both sides of the Atlantic. His final short chapte Morality and pet animals, moreover, brings the ethics of our relationship t苗 animals home in especially thoughtprovoking ways.

Despite its occasionally repetitive rhetoric, its omissions, the attribution (page 93) of 'we murder to dissect' to. Tennyson rather than Wordsworth and some clumsy carpentry in the make-up of the new edition, Anim Rights and Human Morality remains one of the most accessible, sympro thetic and challenging introductions. to an important area of current mord debate, whose complexities Rollin, acknowledges and enlightens.

KENNETH M BOYWू Institute of Medical Ethics Edinburgf

The rights of patients

George J Annas, Clifton, New Jersey Humana Press Inc, 1992, 328 pages $\$ 27.50$ 